КУЗНЕЦОВ Никита Максимович - аспирант кафедры американских исследований факультета международных отношений Санкт-Петербургского государственного университета (199034, Россия, г. Санкт-Петербург, Университетская наб., 7-9, nmkuznetsov@list.ru)

\title{
SHARP POWER И ВНЕШНЯЯ ПОЛИТИКА США: СОЧЕТАНИЕ НЕСОЧЕТАЕМОГО?
}

\begin{abstract}
Аннотация. Статья оценивает дискурс вокруг концепции внешнеполитического влияния sharp power («острая сила»). Sharp power рассматривается западными авторами как антипод soft power («мягкой силы»), которая характеризует дестабилизирующую «демократические» страны деятельность «авторитарных» держав. Подобные формулировки вызывают ряд вопросов относительно субъективности и академической глубины новой концепции. Анализируя тенденции в публичной дипломатии США, автор выявляет основные цели и направления современного информационного влияния Вашингтона и делает вывод об идеологическом, а не научном значении концепции “острой силы».

Ключевые слова: “острая сила», «мягкая сила», “умная сила», пропаганда, информационные операции, публичная дипломатия, цифровая дипломатия, дипломатия данных, США
\end{abstract}

\section{Введение}

Концепция «мягкой силы» (soft power), введенная в 1990-х гг. профессором Гарвардского университета Джозефом Наем, стала универсальным описанием любых невоенных форм внешнеполитической деятельности государств [Nye 1990; 2004]. Однако с 2017 г. западные эксперты стали предпринимать попытки отделить «мягкую силу» от информационного влияния некоторых стран. В настоящее время внимание мирового сообщества приковано к концептуальным особенностям и методам реализации так называемой острой силы (sharp power). Именно так американские исследователи Кристофер Уолкер и Джессика Людвиг назвали форму власти «автократий», публичная дипломатия которых, подобно ножу, «вонзается» в социальный строй зарубежного государства с целью его дестабилизации ${ }^{1}$.

Исследования понятия sharp power проводятся в рамках трех направлений. В одних трудах sharp power рассматривается как форма власти «авторитарных режимов» (в первую очередь России, Китая и Ирана) [Walker 2018; Yenna 2019]. Вторая группа изысканий посвящена методологии изучения «острой силы» как нового феномена международных отношений [Hanouna et al. 2019]. Однако все большее число исследователей задаются вопросом о правомерности выделения sharp power в отдельную концепцию. Отмечается, что «острая сила» может являться идеологической манипуляцией и «пропагандистским клише» западных авторов, а ее целью стало буквальное разделение публичной дипломатии на «свою» и «чужую» [Shaо 2019; Махмуд 2020; Кузнецов 2021].

Так, встает вопрос о роли методов sharp power во внешней политике «демократических» стран. В особенности нас интересуют информационные операции США, т.к. именно американские эксперты начали дискурс об «острой силе». Ведь определение sharp power как вредоносной деятельности «недемократических режимов» может являться попыткой западных авторов, наиболее приближенных к реальному процессу принятия внешнеполитических решений, обелить использование западными государствами низкоморальных методов

1 Walker C., Ludwig J. 2017. The Meaning of Sharp Power. How Authoritarian States Project Influence. - Foreign Affairs. URL: https://www.foreignaffairs.com/articles/china/2017-11-16/ meaning-sharp-power (accessed 09.01.2022). 
внешней политики и сохранять при этом ярлык вредоносности информации в проектах публичной дипломатии стран-оппонентов.

\section{Sharp Power: от практики к теории?}

Развитие мягкой силы привело к потере Соединенными Штатами единоличной монополии на информационное доминирование в мире, тогда как традиционные оппоненты Вашингтона в лице России и Китая смогли укрепить свое влияние [Цветкова, Кузнецов 2020: 30].

K. Уокер и Дж. Людвиг положили начало дискурсу о новой форме внешнеполитического влияния, являющейся прямой противоположностью концепта «мягкой силы». Согласно экспертам, sharp power - это форма власти, инструменты которой являются не принудительными с точки зрения «жесткой силы» ( hard power $)^{1}$, но и не мягкими по своей сути ${ }^{2}$. «Острая сила» не имеет ничего общего с привлекательностью и притяжением, составляющими сущность soft power. Цель sharp power - дестабилизация политического и социального строя страны-мишени [Walker 2018].

Так, одной из задач «острой силы», по мнению экспертов, является подрыв избирательных процессов и внутренний раскол демократий [Walker 2018]. Тезис о том, что «авторитарные режимы» влияют на выборы западного сообщества, дал старт очередному витку развития феномена sharp power. Статья К. Уокера была опубликована в самый разгар политического кризиса в США и обвинений России в осуществлении целенаправленного информационного влияния, определившего исход президентских выборов в 2017 г. Так, вместо привычных теоретико-философских изысканий о пропаганде впервые стали появляться труды авторов, визуализирующих sharp power при помощи специального компьютерного софта и анализа цифровых данных. Эксперты выявляли интернет-троллей (реальных пользователей, в чьи задачи входят дискредитация политических лидеров, распространение негативных комментариев и фейковых новостей), проводили сентимент-анализ текстов российских и китайских каналов иновещания, рассматривали анализ «больших данных» (Big Data) как новый императив современной внешней политики [Hanouna et al. 2019].

Эксперты принялись разрабатывать новые способы сдерживания «пагубного влияния» (malign influence), которое оказывают «авторитарные державы» и их «острая сила». Ограничение работы СМИ, мозговых центров и академических программ, разработка методов выявления пропаганды и «улучшение работы с аудиторией» стран - распространителей sharp power (контрпропаганда) стали их ключевыми рекомендациями [Yenna 2019].

К методам sharp power западные эксперты относят 1) распространение пропаганды; 2) использование чат-ботов (автоматизированных программ, имитирующих диалог с интернет-пользователями) и интернет-троллей; 3) хакерские атаки на базы данных; 4) аналитику цифровых данных об интернет-аудитории и иные «дешевые, но эффективные» кибероперации. Невозможно не обратить внимание на еще одно утверждение К. Уокера и Дж. Людвиг, согласно которому методологический набор sharp power не имеет никакого значения. По их мнению, абсолютно любые направления публичной дипломатии «авторитарных» Китая и России представляют угрозу из-за того, что весь их внешнепо-

\footnotetext{
1 Hard power - форма политической власти, предполагающая применение военного или экономического принуждения.

2 Walker C., Ludwig J. 2021. The Long Arm of the Strongman. How China and Russia Use Sharp Power to Threaten Democracies. - Foreign Affairs. URL: https://www.foreignaffairs.com/ articles/china/2021-05-12/long-arm-strongman (accessed 09.01.2022).
} 
литический курс направлен на «подавление демократии» и «инакомыслия» 1 . Обязательной оговоркой в трудах западных экспертов стал тезис о том, что sharp power является собирательным термином, отражающим все «коварство», «хитрость» и «агрессивность» внешней политики Китая, России и других «автократий». Западные авторы убеждают аудиторию в том, что такие методы присущи исключительно авторитарным и тоталитарным режимам, а не «свободным демократиям» ${ }^{2}$.

При этом идентифицируемые как sharp power методы влияния оказали колоссальное влияние на цифровую дипломатию (digital diplomacy) в глобальном масштабе. Именно пропаганда в социальных сетях, аналитика Big Data о зарубежной аудитории, чат-боты и целый арсенал инструментов по борьбе с информационной активностью стран-оппонентов стали инструментами современной публичной дипломатии [Цветкова, Кузнецов 2020: 31].

Таким образом, методы sharp power стали нормой современных международных отношений. При этом сам термин «острая сила» оказался ярлыком для любой информационной активности России, Китая, Ирана и других стран, традиционно идентифицируемых США как национальная угроза.

\section{«Острая сила» по-американски}

Некоторые исследователи констатируют, что sharp power является ложной концепцией. В частности, отмечается, что ей не хватает академической логики и четкого разделения с «мягкой»/«жесткой» силой [Shao 2019: 142]. Подчеркивается, что западные эксперты усовершенствовали sharp power и стали применять ее методы «на опережение» против оппонентов, продолжая при этом «изображать из себя жертв» «острой силы» [Леонова 2019: 22].

Так, ставится под сомнение отсутствие ангажированности в факте нарицания внешней политики оппонентов США «острой» и «коварной» экспертами, фактически работающими на американское правительство [Махмуд 2020: 198]. К. Уокер и Дж. Людвиг, авторы первых трудов о sharp power, являются сотрудниками американского Национального фонда в поддержку демократии. Получающий щедрые ассигнования от конгресса США институт традиционно считается агентом «мягкой» (т.е. «хорошей», а не низкоморальной и «острой») силы, чья миссия заключается в «содействии становлению и развитию демократии и свободы во всем мире» - вмешательстве во внутреннюю политику зарубежных стран, предоставлении денежных средств определенным политическим кругам, диссидентским движениям и т.д. В 2015 г. фонд стал первой в России «нежелательной организацией», представляющей угрозу ее конституционному строю ${ }^{3}$. Отмечается, что фонд был напрямую вовлечен в процессы смены политических режимов («цветных революций») в Грузии (2003-2004 гг.), Украине (2013-2014 гг.) и т.д. [Махмуд 2020: 197]. В 2021 г. руководство фонда подверглось розыгрышу (prank call). Уверенные в том, что проводят видеоконференцию с лидерами белорусской оппозиции, лидеры фонда признались в

\footnotetext{
1 Walker C., Ludwig J. 2017. The Meaning of Sharp Power. How Authoritarian States Project Influence. - Foreign Affairs. URL: https://www.foreignaffairs.com/articles/china/2017-11-16/ meaning-sharp-power (accessed 09.01.2022).

2 McClintock B. 2017. Russian Information Warfare. - RAND. URL: https://www.rand.org/ blog/2017/07/russian-information-warfare-a-reality-that-needs-a.html (accessed 09.01.2022).

3 Заместитель генерального прокурора РФ Владимир Малиновский подписал решение о признании нежелательной на территории РФ деятельности иностранной неправительственной организации «Национальный фонд в поддержку демократии». Доступ: http:// genproc.gov.ru/smi/news/genproc/news-832994/ (проверено 09.01.2022).
} 
финансировании протестных движений в России и «скромном, но значительном» вкладе в организацию митингов в Республике Беларусь ${ }^{1}$.

Поэтому с практической точки зрения доказательством наличия собственной sharp power у США (в случае признания данной категории реальной концепцией) может стать анализ ее публичной дипломатии. Американская внешняя политика традиционно изучается с точки зрения четырех концепций: «мягкой силы», «жесткой силы», «умной силы» (smart power) и стратегической коммуникации (strategic communication).

Понятие «умная сила» было предложено Дж. Наем в нулевых годах как «способность сочетать жесткую и мягкую силу для формирования выигрышной стратегии» ${ }^{2}$. Поклонница данной теории госсекретарь США Хиллари Клинтон (2009-2013 гг.), заявляла, что дипломатия США должна сочетать в себе полный набор любых доступных инструментов ${ }^{3}$. Отмечается, что воздействие США на зарубежную аудиторию стало варьироваться от установления диалога, сотрудничества и распространения ценностей до влияния на выборы, смены политического режима, использования массивов пропаганды и создания хаоса для дестабилизации стран-оппонентов [Цветкова, Кузнецов 2020: 31].

Стратегическая коммуникация, или «диалоговая пропаганда» официально стала основой публичной дипломатии США в 2013-2014 гг. [Цветкова 2015: 125]. США принялись анализировать запросы целевой аудитории (listening), создавать эффективный диалог с аудиторией, реагировать на пропаганду оппонентов, задействовать новые каналы распространения новостей и увеличивать финансирование проектов цифровой дипломатии 4 . Интересно заметить, что именно распространение пропаганды, скорость информационных потоков и желание дестабилизировать зарубежные институты власти и общества Дж. Най называет ключевыми характеристиками sharp power ${ }^{5}$. Но если предпринимаемые Соединенными Штатами шаги по информационному доминированию в мире западные эксперты концептуализируют «мягкой силой» или стратегической коммуникацией, то аналогичные действия стран - оппонентов Вашингтона идентифицируются ими как «острые» и «коварные».

Основными каналами распространения пропаганды и проведения киберопераций Россией и Китаем эксперты по sharp power называют социальные сети и СМИ 6 . При этом информационное влияние «жертвы» sharp power в лице США продолжает расти с каждым годом. В период с 2017 по 2021 г. Агентство по глобальным медиа, курирующее американское международное вещание, получило около 3,5 млрд долл. финансирования. Основными целями иновещания США являются: 1) распространение американских ценностей; 2) разъяснение

\footnotetext{
${ }^{1}$ Bennetts M. We fund Russian democracy protesters, boasts US group. - The Times. URL: https://www.thetimes.co.uk/article/russian-pranksters-trick-us-officials-into-boasting-aboutfunding-protests-hbtwtvg6n (accessed 09.01.2022).

2 Nye J. 2006. In the Mideast, the goal is "smart power". - Boston Globe. Доступ: http://archive. boston.com/news/globe/editorial_opinion/oped/articles/2006/08/19/in_mideast_the_goal_is_ smart_power (accessed 24.09.2021).

3 Ethnerige E. 2009. How Soft Power Got Smart. - The New York Times. URL: https:// opinionator.blogs.nytimes.com/2009/01/14/how-soft-power-got-smart/ (accessed 09.01.2022).

4 A Strategy for Countering Terrorist Propaganda in the Digital Age. URL: https://2009-2017. state.gov/r/cscc/releases/243877.htm (accessed 09.01.2022).

5 Nye J. 2018. How Sharp Power Threatens Soft Power. The Right and Wrong Ways to Respond to Authoritarian Influence. - Foreign Affairs. URL: https://www.foreignaffairs.com/articles/ china/2018-01-24/how-sharp-power-threatens-soft-power (accessed 09.01.2022).

6 Walker C., Ludwig J. 2017. The Meaning of Sharp Power. How Authoritarian States Project Influence. - Foreign Affairs. URL: https://www.foreignaffairs.com/articles/china/2017-11-16/ meaning-sharp-power (accessed 09.01.2022).
} 
политики США широкой аудитории; 3) противостояние «пропаганде страноппонентов»; 4) освещение негативных черт развития зарубежного общества ${ }^{1}$. Подобная деятельность американских каналов иновещания логично вписывается в концепцию sharp power. Ведь Дж. Най отмечает, что одной из главных целей «острой силы» является «манипулирование общественным мнением и желание продемонстрировать слабость существующего в стране-мишени политического режима» 2 .

В настоящее время осуждающие sharp power американские эксперты призывают Белый дом усиливать цифровую дипломатию: «заглушать» информацию стран-оппонентов в сети посредством изменения алгоритмов поисковых запросов, а также использовать инструменты «машинного типа» ${ }^{3}$. Речь идет даже о создании специального отдела госдепартамента США, сотрудники которого будут отвечать за активность американских интернет-троллей и ботов в социальных сетях. И если обработка Big Data об интернет-пользователях Китаем или Россией называется ими «цифровым колониализмом» 4 , то аналогичные действия «демократий» не подвергаются осуждению. С 2016 г. Вашингтон развивает дипломатию данных (data diplomacy) - обособленное направление внешней политики, направленное на информационное сдерживание стран-оппонентов и увеличение эффективности проектов внешней пропаганды [Цветкова, Кузнецов 2020]. Ее основу составляет интеллектуальный анализ цифровых данных, позволяющий обрабатывать большие объемы информации, генерируемые пользователями в социальных сетях. С 2018 г. финансирование Центра глобального взаимодействия при Госдепартаменте США - института американской дипломатии данных стало достигать до 138 млн долл. ежегодно 5 . В официальных отчетах ведомства указывается, что разработка новых методов анализа Big Data, развитие технологий искусственного интеллекта и способов борьбы с цифровой дипломатией стран-оппонентов, а также «стимулирование эффективности сообщений, направленных на популяризацию имиджа США» остаются ключевыми задачами нового направления американской внешней политики.

\section{Заключение}

Проведенный анализ заставляет усомниться в правомерности выявления «своей» «мягкой силы» у западных стран и «чужой», низкоморальной «острой силы» у «авторитарных режимов». Подобные манипуляции ставят перед собой лишь одну цель - ослабить информационное воздействие стран-оппонентов. Sharp power может быть расценена как не конкретизированный набор методов публичной дипломатии, но не как обособленная от «мягкой силы» научная концепция. Россия, Китай и другие страны смогли наглядно продемонстрировать Соединенным Штатам, что информационное доминирование в мире

1 BBG Strategic Plan 2018-2022. - U.S. Agency for Global Media. URL: https://www. usagm.gov/wp-content/uploads/2018/02/BBG-Strategic-Plan-2018-2022_FINAL.pdf (accessed 09.01.2022).

2 Nye J. 2018. How Sharp Power Threatens Soft Power. The Right and Wrong Ways to Respond to Authoritarian Influence. - Foreign Affairs. URL: https://www.foreignaffairs.com/articles/ china/2018-01-24/how-sharp-power-threatens-soft-power (accessed 09.01.2022).

3 McFaul M. 2021. How to Contain Putin's Russia. - Foreign Affairs. URL: https://www. foreignaffairs.com/articles/ukraine/2021-01-19/how-contain-putins-russia (accessed 09.01.2022).

4 Ashbrock C. 2020. From Digital Diplomacy to Data Diplomacy. URL: https://www.ipsjournal.eu/topics/foreign-and-security-policy/from-digital-diplomacy-to-data-diplomacy-3993/ (accessed 10.01.2022).

52020 Comprehensive Annual Report on Public Diplomacy and International Broadcasting. URL: https://www.state.gov/2020-comprehensive-annual-report-on-public-diplomacy-andinternational-broadcasting/ (accessed 09.01.2022). 
может принадлежать не только Вашингтону. Публичная дипломатия США, в свою очередь, доказывает тот факт, что sharp power - это не форма власти, используемая недружественными западному сообществу странами, а лишь очередные инструменты влияния в эпоху информационного противоборства.

\section{Список литературы}

Кузнецов Д.В. 2021. «Острая сила» в современном политическом дискурсе стран Запада и внешняя политика России и Китая. - Проблемы Дальнего Востока. № 3. С. 145-159.

Леонова О.Г. 2019. Sharp Power - новая форма внешнеполитического влияния в глобальном мире. - Мировая экономика и международные отношения. № 2. С. 21-28.

Махмуд А.X. 2020. Sharp power. Попытка западных авторов разделить мягкую силу на «свою» и «чужую». - Вестник РГГУ. Сер. Политология. История. Международные отношения. № 4-2. С. 186-202.

Цветкова Н.А. 2015. Публичная дипломатия США. - Международные проиессы. № 3. С. 121-133.

Цветкова Н. А., Кузнецов Н.М. 2020. Феномен дипломатии больших данных в мировой политике. - Вестник РГГУ. Сер. Политология. История. Международные отношения. № 4. С. 27-44.

Hanouna S., Neu O., Pardo S., Tsur O., Zahavi H. 2019. Sharp Power in Social Media: Patterns from Datasets across Electoral Campaigns. - Australian and New Zealand Journal of European Studies. Vol. 11. No. 3. P. 97-113.

Nye J.S., Jr. 1990. Bound to Lead: The Changing Nature of American Power. N.Y.: Basic Books. 307 p.

Nye J.S., Jr. 2004. Soft Power. The Means to Success in World Politics. N.Y.: Public Affairs. 208 p.

Shao J. 2019. Exploring China's "Sharp Power": Conceptual Deficiencies and Alternatives. - Transcommunication. Vol. 6-2. P. 129-148.

Walker C. 2018. What Is Sharp Power? - Journal of Democracy. Vol. 29. Is. 3. P. 9-23.

Yenna W .2019. Recognizing and Resisting China's Evolving Sharp Power. American Journal of Chinese Studies. Vol. 26. No. 2. P. 129-153.

\section{SHARP POWER AND U.S. FOREIGN POLICY: A COMBINATION OF THE INCOMBINATIBLE?}

\footnotetext{
Abstract. The article observes the discourse about the methodological and theoretical frameworks of the sharp power's concept. Since the first publications about sharp power in 2017, this concept has already become the central issue of all researches on public diplomacy in the world. Sharp power observed by western researchers as the antipode of soft power, which is used by «authoritarian regimes» (including Russia, China, Iran and a number of other states) to destabilize "democratic» countries. Such formulations raise a number of questions regarding the subjectivity and academic depth of the new concept. An analysis of U.S. public diplomacy demonstrates that the Western community officially condemns sharp power methods. The author makes a conclusion about the fake and ideological meaning of sharp power and the formation of its methods as a trend in modern international relations.

Keywords: sharp power, soft power, smart power, propaganda, informational operations, public diplomacy, digital diplomacy, data diplomacy, USA
} 